\title{
AN EXPERIMENTAL STUDY OF THE IMMEDIATE HEMODY- NA.MIC ADJUSTMENTS TO ACUTE ARTERIOVENOUS FISTULAE OF VARIOUS SIZES ${ }^{1}$
}

\author{
BY CHARLES W. FRANK, HSUEH-HWA WANG,2 JACQUES LAMMERANT, ${ }^{3}$ \\ ROBERT MILLER, AND RENÉ WÉGRIA \\ (From the Department of Medicine, Columbia University College of Physicians and Surgeons, \\ and the Presbyterian Hospital, New York, N. Y.)
}

(Submitted for publication November 17, 1954; accepted January 26, 1955)

In the past thirty years, numerous observations have been made on the hemodynamic effects of arteriovenous fistulae. Arteriovenous fistulae of variable size and location have been studied in patients as well as in animals. Such studies have consisted a) in observing the effect of suddenly opening and closing a fistula in acute experiments, b) in studying the effects of suddenly closing and opening a fistula in an animal or a patient who had had such a fistula for a relatively long time, and c) in recording the effect of complete surgical eradication of a long-standing fistula. While some agreement has been reached on many points, there persists some controversy about most of them (1). It is now generally agreed that an acute as well as a chronic arteriovenous fistula increases the cardiac output (1-8). However, Lewis and Drury (9) came to the conclusion that the cardiac output is not increased unless the arteriovenous shunt is very large. Van Loo and Heringman (10) concluded that acute arteriovenous fistulae increase the cardiac output although the flow of blood in certain vascular areas outside the fistula circuit is decreased. The venous pressure is definitely increased near the site of the arteriovenous communication, but most investigators have found that the increment of venous pressure decreases rapidly as the pressure is measured further down the venous bed toward the right atrium, and in the venae cavae and right atrium the pressure is elevated little or not at all

1 This work was made possible by a grant-in-aid from the New York Heart Association, the Sidney A. Legendre Gift, and the Charles A. Frueauff Gift. It was presented at the Annual Meeting of the American Physiological Society in New York City in 1952.

2 Fellow of the New York Heart Association.

8 Fulbright Fellow, from the Department of Medicine, University of Louvain Medical School, Louvain, Belgium.
$(3,4,11)$. However, one group of workers (12) has reported more striking increases of right atrial pressure in dogs with an arteriovenous fistula. The blood volume seems to be increased by an arteriovenous fistula of a certain size and duration $(3,13)$ although some observers (4) suggest that this increase in blood volume occurs only in the presence of an incipient or frank cardiac failure.

Since the magnitude of the effects of an arteriovenous fistula would seem $a$ priori to depend upon the volume of blood shunted through the abnormal pathway, it is rather surprising that in no study has any attempt been made to measure simultaneously the rate of flow through the fistula and the other functions of interest such as cardiac output, arterial and venous pressures. The present study was undertaken in an attempt to determine the acute cardiovascular adjustments to arteriovenous fistulae of different sizes, by recording simultaneously and continuously the flow of blood through the fistula, the flow of blood into the systemic circulation exclusive of the arteriovenous fistula circuit, the mean arterial blood pressure and the mean central venous pressure.

\section{METHODS}

Fifteen dogs weighing between 13 and 28 kilograms were anesthetized by the intravenous infusion of 100 milligrams of chloralose per kilogram of body weight. The chest was opened by a midsternal incision, and respiration was maintained by a positive pressure respirator. Segments of the brachiocephalic trunk, subclavian artery, common carotid arteries, upper part of the descending aorta, as well as the femoral veins were exposed and dissected. Ten milligrams of heparin per kilogram of body weight were then administered intravenously and repeated injections of one-half that amount were given every half hour. Cannulation of the arteries mentioned above was then performed in a manner previously described (14) and as pictured by the diagram of Figure 1. 
The tube with the tunnel clamp $\mathrm{T}$ leads into the central end of a femoral vein. When clamp $T$ is screwed tight, the blood expelled by the left ventricle leaves the aortic arch via the brachiocephalic and subclavian arteries, and after passing through rotameter $A$, flows into the descending aorta and common carotid arteries. This flow will be referred to as the body flow, and was measured and recorded continuously by rotameter $A$. When the fistula to the femoral vein was opened by unscrewing tunnel clamp $T$, the flow of blood through the fistula was measured and recorded continuously by rotameter B. Thus, when the fistula was.patent, the cardiac output was equal to the sum of the two recorded flow rates. Each rotameter was supplemented with a shunt $S$ to allow the recording of the zero flow without interruption of the circulation. When blood flows were being measured, the shunts were occluded by clamps. The mean arterial blood pressure and the mean venous pressure were recorded by damped Gregg optical manometers of suitable sensitivity. The venous pressure was recorded from the point of entrance of the superior vena cava into the right atrium. Clamp $T$ was unscrewed so as to open the fistula progressively and reach the desired level of fistula flow over a period of from one-half to one minute; from the time of the unscrewing of Clamp $T$, the fistula was maintained open for five minutes or longer, then it was suddenly occluded. Continuous photographic records of pressures and flows were obtained during a control period, during the time the fistula was patent, and during a recovery period which followed the occlusion of the fistula. An example of the type of record obtained is illustrated in Figure 2. To facilitate the presentation

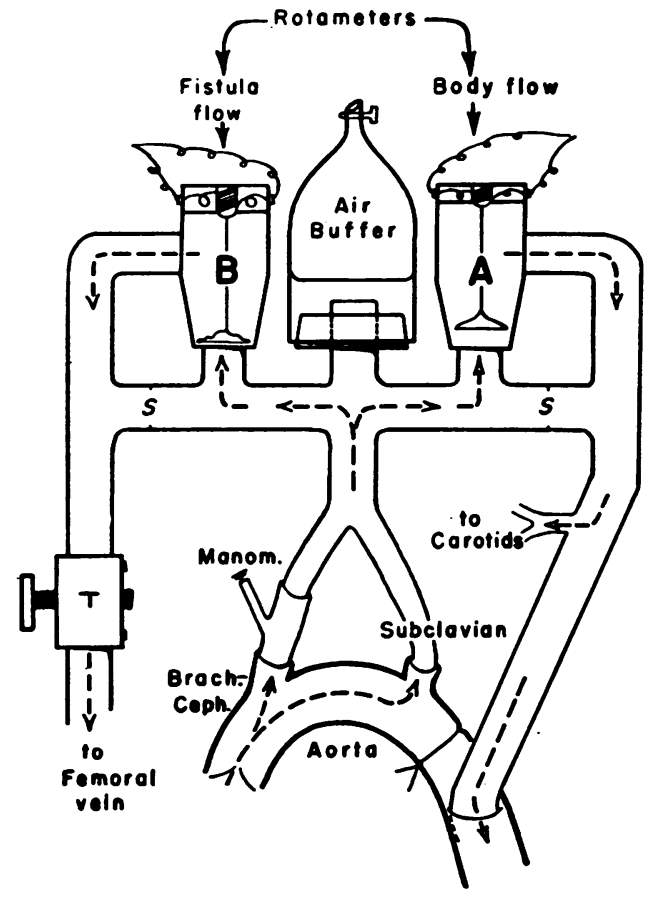

Fig. 1. Diagram of the Technigue Used to Produce Arteriovenous Fistulae and to Measure and Record Continuously and Separately the Flow of Blood Through the Fistula (Fistula Flow) and the Flow of Blood to the Rest of the Body (Body Flow)-Explanation in Text

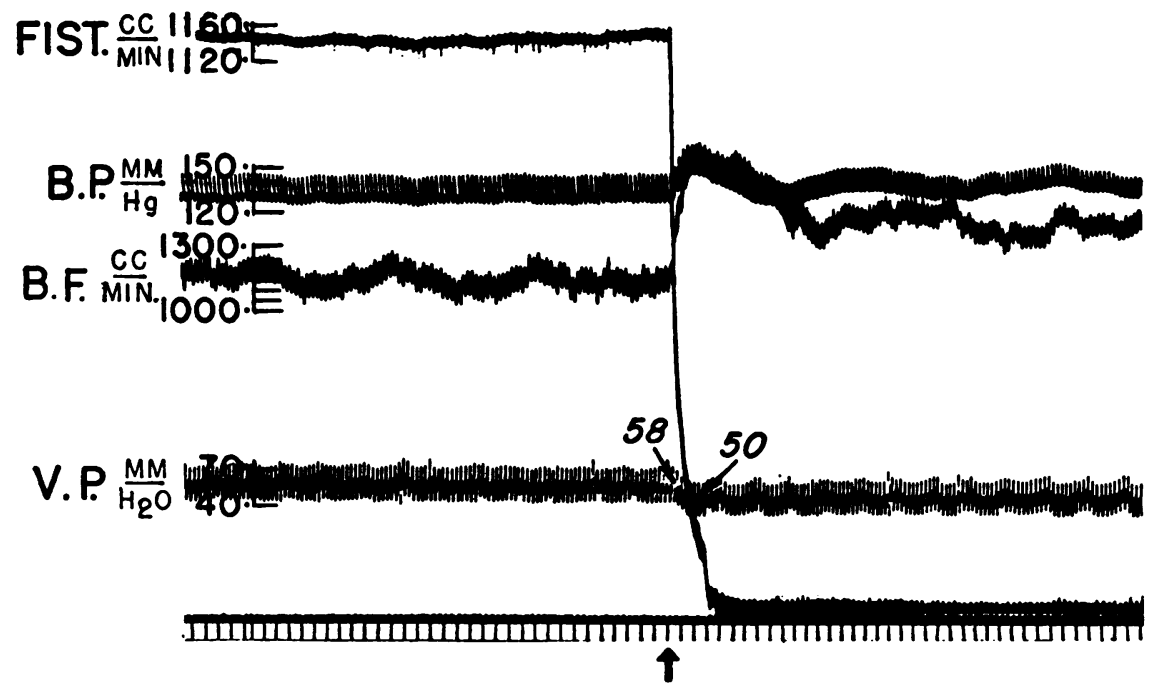

Fig. 2. Continuous Record Obtained During the Patency of an Arteriovenous Fistula and After Its Sudden Occlusion

At the beginning of the record, from top to bottom, fistula flow, mean arterial blood pressure, body flow and venous pressure. At the arrow, sudden occlusion of the arteriovenous fistula. Scale for the flows in cc. per minute; scales for the arterial blood pressure and the venous pressure in $\mathrm{mm}$. of mercury and water, respectively. 


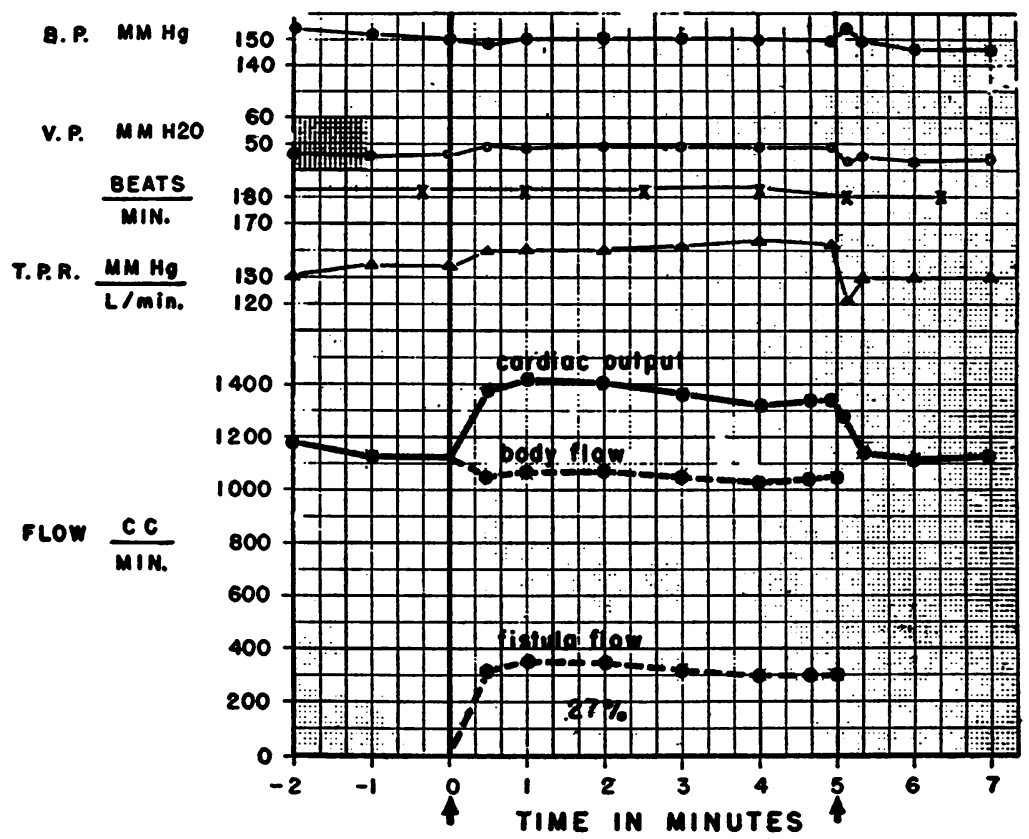

Fig. 3. Plot of an Experiment in Which an Arteriovenous Fistula Accommodating Approximately 27 Per Cent of the Control Cardiac Output Was Produced

From top to bottom, mean arterial blood pressure in mm. of mercury; venous pressure in mm. of water; heart rate per minute; body total peripheral resistance in arbitrary units; cardiac output, body flow and fistula flow in cc. per minute. At the first and second arrow, opening and closing of fistula, respectively. Time in minutes.

and analysis of the data the results of each experiment were plotted on graph paper as indicated in the succeeding figures. The resistance to the body flow or body total peripheral resistance (TPR) was calculated in arbitrary units by dividing the mean arterial blood pressure expressed in $\mathrm{mm}$. of mercury by the body flow expressed in liters per minute.

\section{RESULTS}

Fifty fistulae of various size were studied in 15 dogs. Examples of the hemodynamic adjustments to small, medium and large fistulae are illustrated by Figures 3, 4, and 5 .

Figure 3 is the plot of an experiment in which was produced an arteriovenous fistula accommodating approximately $300 \mathrm{cc}$. per minute, which amounted to approximately 27 per cent of the control cardiac output. During the control period, two minutes of which are shown in Figure 3, the mean arterial blood pressure oscillated between 150 and $154 \mathrm{~mm}$. of mercury, the cardiac output ranged between 1120 and $1170 \mathrm{cc}$. per minute, and the central venous pressure varied from 45 to 46 $\mathrm{mm}$. of water. The body total peripheral resistance ranged between 130 and 135 units. Immediately upon opening the fistula, the cardiac output increased and thirty seconds after the beginning of the opening of the fistula, the fistula flow amounted to 320 . cc. per minute, the body flow had decreased slightly to $1080 \mathrm{cc}$. per minute, and the cardiac output was 320 plus 1080 , or 1400 cc. per minute. During the five-minute period that the fistula was patent, the mean arterial blood pressure remained within its control range, and in view of the slight decrease of the body flow it is apparent that some increase in the peripheral resistance to body flow was present, the TPR reaching a peak value of 144 units. A slight increase in central venous pressure was recorded during this fistula. After five minutes the fistula was suddenly closed. The body flow immediately increased and reached a maximal value of 1280 cc. per minute within six seconds, then returned to its control level of $1140 \mathrm{cc}$. per minute within 


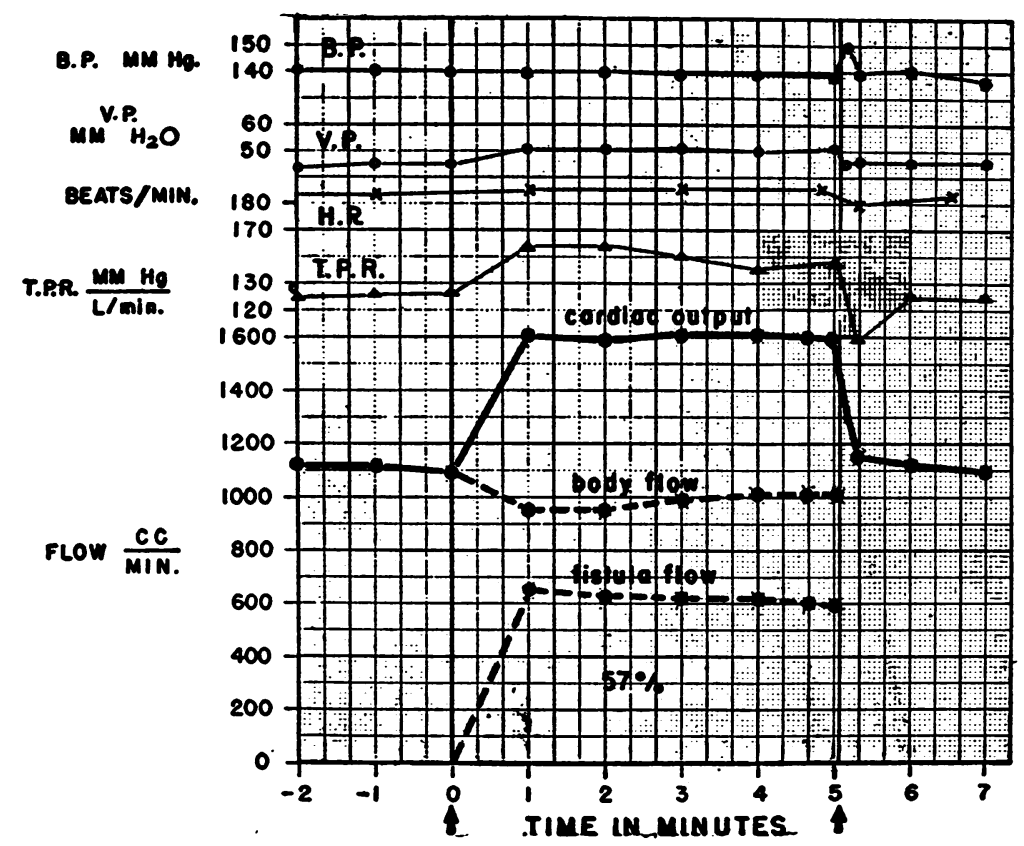

Fig. 4. Plot of an Expertment in Which an Arteriovenous Fistula Accommodating Approxmately 57 Per Cent of the Control Cardac Output Was Produced

Same legend as in Figure 3.

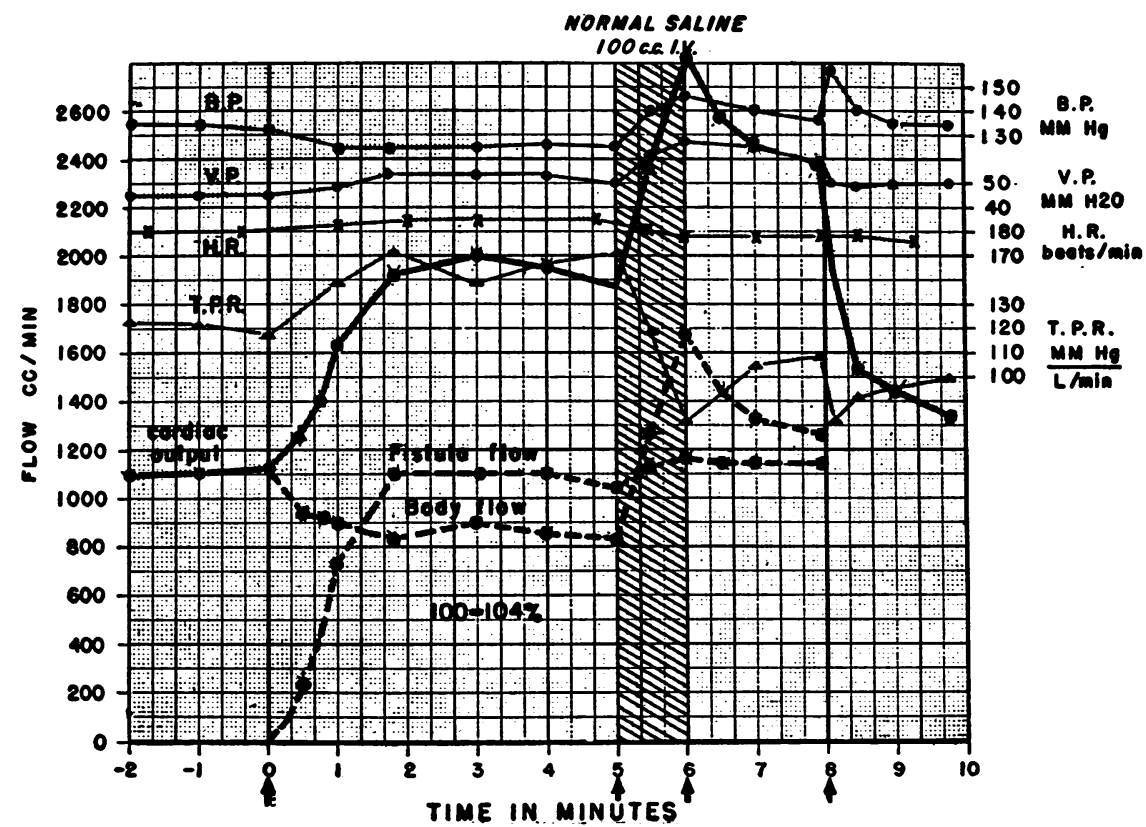

Fig. 5. Plot of an Experiment in Which an Arteriovenous Fistula Accommodating 100 to 104 Per Cent of the Control Cardiac Output Was Produced

From top to bottom, mean arterial blood pressure in mm. of mercury; venous pressure in mm. of water; heart rate per minute; body total peripheral resistance in arbitrary units; cardiac output, body flow and fistula flow in cc. per minute. At first and fourth arrows, opening and closing of fistula, respectively. Between second and third arrows, intravenous infusion of $100 \mathrm{cc}$. of isotonic sodium chloride solution. Time in minutes. 
15 seconds of the time of the occlusion of the fistula. The mean arterial blood pressure also exhibited a transient increase of $5 \mathrm{~mm}$. of mercury during this 15-second period immediately following the closing of the fistula. A distinct fall of the central venous pressure was recorded after the closure of the fistula. No significant changes in heart rate were noted. In summary, it is apparent that this fistula, accommodating a blood flow equivalent to around 30 per cent of the control cardiac output, caused an increase in cardiac output almost equal to the amount of blood flowing through the fistula so that only a slight decrease in body flow occurred. A fall in arterial blood pressure was prevented by vasoconstriction of the systemic circulation exclusive of the fistula circuit, as manifested by a slight increase in the body total peripheral resistance.

Figure 4 is the plot of an experiment performed on the same dog as that used in the experiment of Figure 3. In this experiment an arteriovenous fistula accommodating a flow of $600 \mathrm{cc}$. per min-

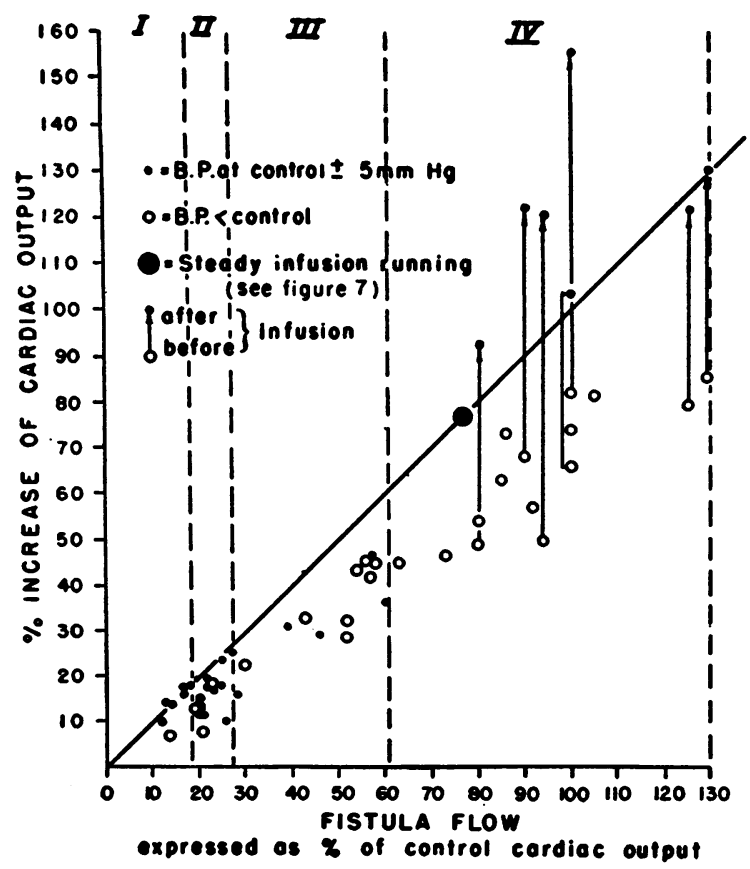

Fig. 6. Composite Plot of the Phenomena Observed in the 50 Fistulae Studied

The percentile increase in cardiac output produced in each fistula is plotted along the ordinate; the corresponding values of the fistula flow expressed in terms of per cent of the control cardiac output are plotted along the abscissa. ute, or 57 per cent of the control cardiac output was produced. Although the increment in cardiac output ( $500 \mathrm{cc}$. per minute) was greater than with the smaller fistula, the increase in cardiac output was insufficient to compensate fully for the fistula flow, and the body flow decreased by $100 \mathrm{cc}$. per minute, a 9 per cent decrease. Body vasoconstriction, manifested by an increase in body TPR from 126 to a peak of 145 units, was effective in maintaining the mean arterial pressure within its control range. An increase of $5 \mathrm{~mm}$. of water in the central venous pressure was present during the patency of the fistula. Upon closing the fistula, the mean arterial blood pressure temporarily rose $10 \mathrm{~mm}$. of mercury above previous and control levels, the body flow rose and remained elevated about 15 seconds, after which the body flow, i.e., the cardiac output, returned to control value. The venous pressure promptly fell to its control level. The heart rate showed no striking change throughout this experiment except for a temporary slowing of five beats per minute immediately after the occlusion of the fistula.

Figure 5 is the plot of the response of the same dog to a fistula accommodating a blood flow of up to $1100 \mathrm{cc}$. per minute, i.e., approximately 100 per cent of the control cardiac output. Although the cardiac output reached a peak of $2000 \mathrm{cc}$. per minute, this increase was clearly inadequate, for the body flow decreased by 200 to $250 \mathrm{cc}$. per minute. Despite the body vasoconstriction revealed by the rise in body TPR, the arterial blood pressure fell $10 \mathrm{~mm}$. of mercury. The central venous pressure rose $9 \mathrm{~mm}$. of water. During the sixth minute of the period during which the fistula was kept open, $100 \mathrm{cc}$. of isotonic sodium chloride solution were administered to the dog via the intact femoral vein. This infusion produced a dramatic increase in cardiac output to a peak of 2840 cc. per minute, an increase of $970 \mathrm{cc}$. per minute above its value just prior to the infusion. However, most of this increment of cardiac output, $850 \mathrm{cc}$. of the 970 cc., was absorbed by the body circulation and only $120 \mathrm{cc}$. went through the fistula circuit. As the body flow rose, there was a marked decrease in the body TPR. Despite this fall in body TPR, the increase in body flow was such that the mean arterial blood pressure rose above its control level. After the end of the infusion, 
the fistula was kept open for another two minutes, during which the effects of the infusion subsided somewhat: cardiac output and body flow as well as venous and arterial blood pressures decreased, whereas the body TPR rose. Upon closing of the fistula the arterial blood pressure rose, then promptly stabilized at its control level; venous pressure and cardiac output fell but remained slightly above control levels, probably because of the persistent effect of the infusion, and the TPR remained below its control value presumably for the same reason.

Figure 6 is a composite plot of the results observed in the 50 arteriovenous fistulae studied. Along the abscissa is plotted the fistula flow expressed as percentage of the control cardiac output. On the ordinate is plotted the corresponding increase in cardiac output expressed in similar terms. To facilitate the discussion, all fistulae have been divided into four groups, delineated by the vertical interrupted lines. The basis for this division of all fistulae into four groups will become apparent in the course of the discussion.
As can be seen in Figure 6, it is clear that the degree of increase in cardiac output is a function of the size of the fistula. In six of the seven fistulae in which the fistula flow was equal to or smaller than 19 per cent of the control cardiac output (Group I), the increase in cardiac output was equal to the fistula flow, so that the body flow remained at its control value, as did the arterial blood pressure and body TPR. The largest fistula in which the increase in cardiac output was equal to the fistula flow accommodated a flow equal to 27 per cent of the control cardiac output. In all the fistulae larger than 27 per cent (Groups III and I.V) and in 11 of the 14 fistulae of Group II, i.e., fistulae equal to 19 to 27 per cent of the control cardiac output, the increment in cardiac output was less than the amount of the fistula flow so that the body flow decreased. Body vasoconstriction as indicated by an increase in the body TPR, was present in all these experiments in which the body flow decreased. Although in all these fistulae the body flow decreased, the mean arterial blood pressure was maintained in 7 of

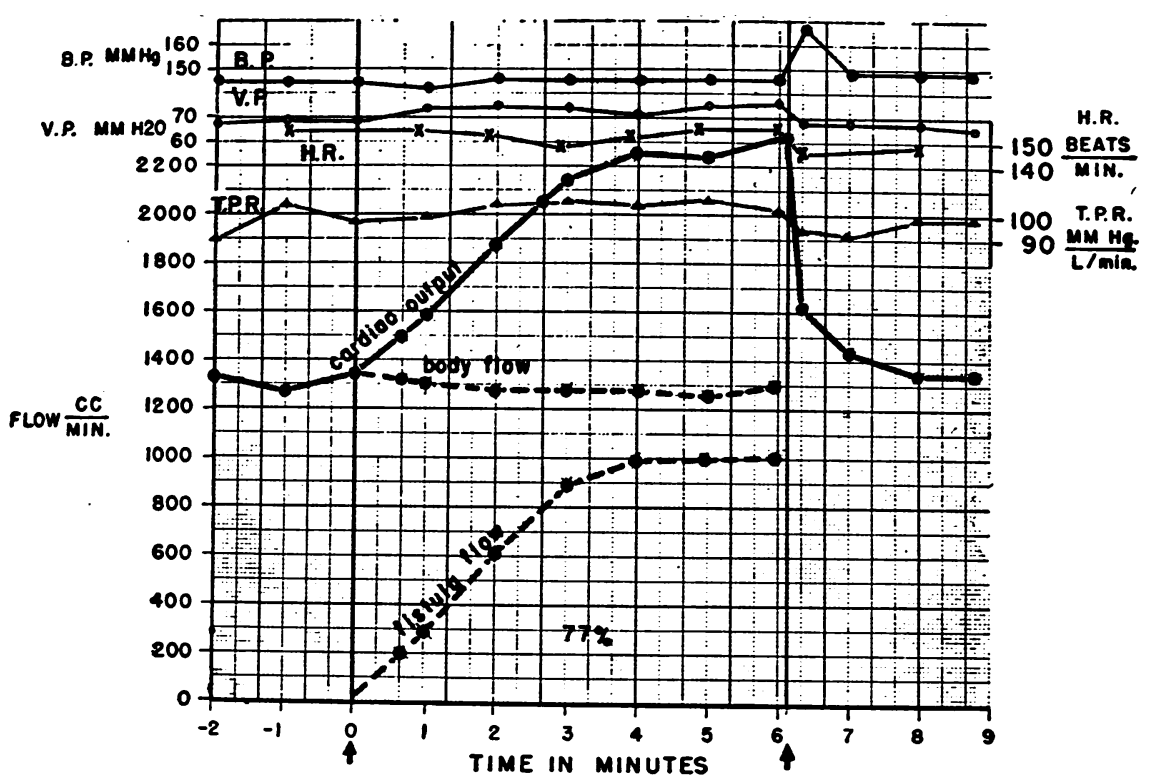

Fig. 7. Plot of an Experiment in Which a Dog Was Given Intravenously Approximately $100 \mathrm{cc}$. of Isotonic Sodium Chloride Solution Over a Period of 10 Minutes, Beginning 1 Minute Before Time 0, the Time at Which the Arteriovenous Fistula Was Opened Progressively Over a Period of 4 Minutes

From top to bottom, mean arterial blood pressure in $\mathrm{mm}$. of mercury; venous pressure in mm. of water; heart rate per minute; body total peripheral resistance in arbitrary units; cardiac output, body flow and fistula flow in cc. per minute. At first and second arrow, progressive opening and sudden closing of arteriovenous fistula, respectively. Time in minutes. 
the 11 fistulae of Group II (experiments represented by solid dots in Figure 6) and in 5 of the 13 experiments of Group III. Group IV comprises 15 large fistulae during which both body flow and mean arterial blood pressure decreased. In seven experiments of Group IV, an infusion of $100 \mathrm{cc}$. of isotonic sodium chloride solution was administered over a one-minute period during the patency of the fistula. During each infusion the cardiac output increased and body flow as well as mean arterial blood pressure rose to or even above control levels. As mentioned in the discussion of Figure 5 , most of the increase in cardiac output was accommodated by the body flow circuit. The increase in cardiac output during these infusions is indicated in Figure 6 by the arrows. The large solid dot of Figure 6 was yielded by the experiment pictured in Figure 7. In this experiment, the dog was given intravenously a continuous infusion of isotonic sodium chloride solution at a constant rate. The total amount of saline solution administered in 10 minutes, from 1 minute before the opening of the fistula to approximately 3 minutes after the closing of the fistula, was approximately $100 \mathrm{cc}$. In this experiment a fistula finally accommodating 77 per cent of the control cardiac output was attained and the cardiac output increased by the full amount of the fistula flow. The central venous pressure rose no more than $6 \mathrm{~mm}$. of water during this fistula. As is apparent from Figure 6, this fistula is almost three times as large as any other fistula found to be fully compensated with respect to body flow without benefit of infusion.

The changes in heart rate, as indicated by the four examples shown in Figures 3, 4, 5, and 7, were slight and variable. As the fistulae were gradually opened, no significant changes were noted. Upon sudden closing of the fistula, a temporary slowing of the heart rate was observed in half of the experiments. The magnitude of this change varied from 5 to 22 beats per minute.

The changes in central venous pressure were slight, but a definite increase was noted in 21 of the 22 fistulae in which the venous pressure was recorded continuously. Table I summarizes the increases seen in central venous pressure with the different sizes fistulae.

\section{DISCUSSION}

An increase in cardiac output was observed in every fistula studied and the magnitude of the increase appeared to be a function of the size of the fistula. Inasmuch as the heart rate did not change consistently or markedly with the progressive opening of the fistula, it might be concluded that the increase in cardiac output was due mainly to an increase in systolic output.

The initial alteration of the circulation upon opening an arteriovenous fistula consists in the opening of a path of less resistance through which blood passes directly from the arterial into the venous part of the vascular bed. The opening of that path of less resistance decreases the resistance to the outflow of blood from the left ventricle, thus producing an increase in the emptying of the left ventricle. In the case of a small fistula, the increase of the venous return is such that the cardiac output is increased by the full amount of the fistula flow, the body flow remains unchanged, and the mean arterial blood pressure is promptly restored to its control level through the increase in cardiac output. It is rather doubtful whether, even in a small fistula, the more complete emptying of the left ventricle ever is the only mechanism through which the increase in venous return occurs and the cardiac output is increased sufficiently to be augmented by the full amount of the fistula flow. Other mechanisms, myocardial as well as peripheral, which may play a role in the acute adjustment to the establishment of an arteriovenous fistula have to be considered, especially in large fistulae. Indeed, upon opening the fistula the inflow of arterial blood into the veins causes a considerable increase in the local venous pressure (11), the veins become distended and the volume of blood in the venous system must be assumed to increase until a new equilibrium is reached. At this point a) the amount of blood leaving the veins per unit of time to enter the right heart is equal to that which enters the venous system coming from the body and the fistula, b) the amount of venous return is larger than before the fistula was opened, and c) the venous system most probably contains more blood than before the opening of the fistula. The rate of venous return in the fistula circuit is determined by the pressure gradient between the veins and the 
heart and obviously the head of pressure in this system is limited for a fistula of a given size by the distensibility of the veins and the volume of blood available to fill them.*

Thus it is suggested that, with the opening of a small fistula, there is an increase in the amount of blood flowing into the venous bed which accommodates a greater volume of blood, then the pressure gradient rises so that the flow of blood into the venous bed is equal to the flow of blood into the right heart. At this new equilibrium, the control cardiac output is increased by the full amount of the fistula flow so that body flow and arterial blood pressure remain at control levels. Such a fistula has been characterized as being fully compensated. However, a redistribution of blood must have occurred, leading to an increase of the blood contained in the venous part of the vascular bed. The source of the blood accounting for the increase in the venous blood volume is not clear. Since there was no evidence of constriction of the arterial tree, at least in the case of a small fistula, it is probable that the increment in the venous blood volume comes not from the arterial tree itself but from blood reservoirs. With larger fistulae a progressively larger volume of blood is pooled in the venous system, and eventually a fistula flow rate is reached at which the pressure gradient is insufficient to ensure an increase in the venous return to the right heart equal to the amount of the fistula flow. Under such circumstances the increase in cardiac output will be less than the amount of the fistula flow and the body flow will fall below control value.

As indicated by experiments similar to that plotted in Figure 7, when the total volume of intravascular blood is increased by the continuous infusion of an isotonic solution of sodium chloride, a much larger fistula is tolerated without decrease in body flow. Similarly, as pictured in Figures 5 and 6 , when a dog with a fistula large enough to produce a decrease in body flow receives an intravenous infusion of isotonic sodium

\footnotetext{
4 Two other factors, the size of the aperture between the arterial and the venous circuit, and the possibility of the development of turbulence at the site of the fistula, have to be considered. The first one is dealt with throughout the manuscript; the second one is not discussed because it is not susceptible of quantitation with the data at hand.
}

chloride solution, the cardiac output may increase by the full amount of the fistula flow or more, and the body flow return to or above control level, although the fistula flow itself is affected relatively little by the infusion. It is therefore most probable that the essential factor which limits the degree of increase in cardiac output in the presence of a large acute arteriovenous fistula is the inadequacy of the venous return and not the cardiac reserve. Furthermore, the critical factor setting the limit to the rate of the venous return is apparently the total available volume of blood. Therefore, the increase in blood volume which develops in chronic arteriovenous fistulae may be interpreted as a beneficial physiological adjustment and not necessarily as an indication of cardiac failure.

The cardiac output increased by the full amount of the fistula flow in 6 out of 7 experiments in which the fistula accommodated up to 19 per cent of the control cardiac output (Group I). In 11 out of the 14 fistulae accommodating a flow equal to from 19 to 27 per cent of the control cardiac output (Group II) and in all fistulae accommodating a flow amounting to more than 27 per cent of the control cardiac output (Groups III and IV), the cardiac output did not increase by the full amount of the fistula flow and the body flow decreased. The total peripheral resistance rose in all those experiments in which the increase in cardiac output was inadequate and, as a result of this vasoconstriction, the mean arterial blood pressure was maintained at control level in 7 out of the 11 experiments of Group II and in 5 of the 13 experiments of Group III. However, despite vasoconstriction, the arterial blood pressure fell in all the experiments in which the fistula accommodated more than 60 per cent of the control cardiac output.

Emphasis has been placed upon the fact that when the fistula is open, the central venous pressure is elevated little or not at all in the presence of a considerable increase of the stroke volume (15). It must be remembered indeed that experiments on the heart-lung preparation indicate that the right auricular pressure has proven to be an insensitive indicator of the rate of venous return, the extent of ventricular filling and the volume of systolic discharge (16). However, as can be seen in Table I, definite, though sometimes slight, in- 
TABLE I

Increases in mean central venous pressure during the different arteriovenous fistulae

\begin{tabular}{cccc}
\hline \hline & $\begin{array}{c}\text { Fistula flow } \\
\text { (expressed in } \\
\text { per cent of } \\
\text { control } \\
\text { cardiac } \\
\text { oumber } \\
\text { of } \\
\text { experi- } \\
\text { ments }\end{array}$ & $\begin{array}{c}\text { Central venous pressure } \\
\text { (mm. of water) }\end{array}$ \\
\hline 8 & $20-30$ & $\begin{array}{c}\text { Mean } \\
\text { increase }\end{array}$ & $\begin{array}{c}\text { Range of } \\
\text { increase }\end{array}$ \\
\hline 7 & $30-60$ & 3.7 & $0-7$ \\
7 & $60-130$ & 5.6 & $3-10$ \\
& & 7.7 & $6-9$ \\
\hline
\end{tabular}

creases in the central venous pressure were recorded during the period that the fistula was patent in 21 out of 22 experiments. It is conceivable that in clinical or experimental studies in which the thorax remained intact and continuous pressure recording was not obtained, changes of this magnitude could remain undetected because of the magnitude of the fluctuations of venous pressure under the influence of respiration. Figure 2 demonstrates the rapidity with which the central venous pressure falls upon closure of the fistula. An abrupt reduction of $8 \mathrm{~mm}$. of water occurred within two seconds. It would seem that this abrupt fall of the central venous pressure is due to the sudden decrease of the rate of venous return. The sudden increase in the resistance to the left ventricular outflow and the reduction in ventricular filling which both occur upon occluding the fistula circuit, would appear to be an adequate explanation for the sudden decrease in stroke volume.

The changes in heart rate which may be observed with the opening and closing of arteriovenous fistulae do not seem to be the essential determinant of the changes in cardiac output, inasmuch as similar responses in output are seen in experiments on animals or humans in which the changes in heart rate are prevented by anesthesia or atropine $(5,8)$.

The data presented may also help the understanding of some of the circulatory adjustments to circumstances other than those resulting from arteriovenous fistulae. Indeed, these observations may be taken to indicate that when in acute situations, vasodilatation occurs in an important vascular area, the degree of increase in venous return attainable without the action of compensatory mechanisms may well be quite limited.

\section{SUMMARY}

Some of the immediate circulatory adjustments to the opening and closing of arteriovenous fistulae of different sizes have been studied in the anesthetized dog. An increase in stroke volume and cardiac output was observed in all experiments. With the smaller fistulae, i.e., fistulae accommodating less than 20 per cent of the control cardiac output, the cardiac output increased by the full amount of the fistula flow. Greater increases in cardiac output occurred with larger fistulae, but the amount of the increase in output was less than the amount of the fistula flow which resulted in a decrease of the blood flow to the systemic capillary bed. Vasoconstriction supervened, which prevented a fall in the mean arterial blood pressure in some of the fistulae accommodating up to 60 per cent of the control cardiac output, but with larger fistulae the arterial blood pressure fell despite vasoconstriction.

It is suggested that the essential factor which limits the degree of increase in cardiac output in the presence of a large fistula is the inadequacy of the venous return, and under the conditions of these experiments, the limit to the rate of venous return seems to be the volume of blood available.

In the light of these findings, the increase in blood volume noted in chronic experimental and clinical arteriovenous fistulae may be considered as a compensatory mechanism, and not necessarily as an indication of the development of cardiac failure.

\section{REFERENCES}

1. McGuire, J., Hauenstein, V., Stevens, C. D., and Sharretts, K. C., Effects of arteriovenous fistulae on the heart and circulation in Blood, Heart and Circulation, F. R. Moulton, ed, publication of the A.A.A.Sc., No. 13, The Science Press, Washington, 1940.

2. Harrison, T. R., Dock, W., and Holman, E., Experimental studies in arteriovenous fistulae: cardiac output. Heart, 1924, 11, 337.

3. Holman, E., Arteriovenous Aneurysm; Abnormal Communications Between the Arterial and Venous Circulations. New York, The Macmillan Co., 1937.

4. Reid, M. R., and McGuire, J., Arteriovenous aneurysms. Ann. Surg., 1938, 108, 643.

5. Elkin, D. C., and Warren, J. V., Arteriovenous fistulas: their effect on the circulation. J.A.M.A., 1947, 134, 1524. 
6. Cohen, S. M., Edholm, O. G., Howarth, S., McMichael, J., and Sharpey-Schafer, E. P., Cardiac output and peripheral bloodflow in arteriovenous aneurysm. Clin. Sc., 1948, 7, 35.

7. Warren, J. V., Nickerson, J. L., and Elkin, D. C., The cardiac output in patients with arteriovenous fistulas. J. Clin. Invest., 1951, 30, 210.

8. Nickerson, J. L., Elkin, D. C., and Warren, J. V., The effect of temporary occlusion of arteriovenous fistulas on heart rate, stroke volume, and cardiac output. J. Clin. Invest., 1951, 30, 215.

9. Lewis, T., and Drury, A. N., Observations relating to arteriovenous aneurism. Heart, 1923, 10, 301.

10. Van Loo, A., and Heringman, E. C., Circulatory changes in the dog produced by acute arteriovenous fistula. Am. J. Physiol., 1949, 158, 103.

11. Nickerson, J. L., Cooper, F. W., Jr., Robertson, R., and Warren, J. V., Arterial, atrial and venous pressure changes in the presence of an arteriovenous fistula. Am. J. Physiol., 1951, 167, 426.
12. Heringman, E. C., Davis, H. A., and Rives, J. D., Effect of acute A-V fistula on circulation time and auricular pressure in dogs. Proc. Soc. Exper. Biol. \& Med., 1945, 60, 371.

13. Warren, J. V., Elkin, D. C., and Nickerson, J. L., The blood volume in patients with arteriovenous fistulas. J. Clin. Invest., 1951, 30, 220.

14. Wégria, R., Frank, C. W., Misrahy, G. A., Sioussat, R. S., McCormack, G. H., and Sommer, L. S., A new technic for the continuous recording of the cardiac output. Proc. Soc. Exper. Biol. \& Med. 1950, 74, 551.

15. Stead, E. A., Jr., and Warren, J. V., Cardiac output in man; an analysis of the mechanisms varying the cardiac output based on recent clinical studies. Arch. Int. Med., 1947, 80, 237.

16. Patterson, S. W., and Starling, E. H., On the mechanical factors which determine the output of the ventricles. J. Physiol., 1914, 48, 357. 